\title{
The Relationship between Epicardial Fat Tissue Thickness and Red Blood Cell Distribution Width in Patients with Type 2 Diabetes Mellitus
}

\author{
Abdulmelik Yildiz, Cennet Yildiz' ${ }^{1}$, Ahmet Karakurt ${ }^{2}$ \\ Department of Cardiology, Nişantaşı University, ${ }^{1}$ Department of Cardiology, Tekden Hospital, Istanbul, ${ }^{2}$ Department of Cardiology, Kafkas University, \\ Cardiology, Kars, Turkey \\ ORCID: \\ Abdulmelik Yildiz: https://orcid.org/0000-0001-8709-9661 \\ Cennet Yildiz: https://orcid.org/0000-0003-2456-3206 \\ Ahmet Karakurt: https://orcid.org/0000-0001-8877-100X
}

\section{Abstract}

Aim: Red blood cell distribution width (RDW) and epicardial fat tissue (EFT) are considered as a novel risk factor for cardiovascular disease. However, their relationship in patients with type II diabetes mellitus (DM) has never investigated before. Materials and Methods: Our study was a single-center prospective study which included 159 diabetic patients and 153 healthy controls. Two-dimensional and M-mode echocardiographic examination was performed using standard apical, parasternal, and subcostal views in all the study participants. Results: EFT thickness and RDW were found to be significantly higher in diabetic patients compared to controls $(4.3 \pm 1.1 \mathrm{~mm}$ vs. $3.7 \pm 1.0 \mathrm{~mm} P=0.001$ and $13.5 \pm 0.7$ vs. $13.2 \pm 0.9 P=0.044$, respectively). EFT thickness and RDW were positively correlated. RDW value of 13.55 predicted EFT thickness $>5 \mathrm{~mm}$ with a sensitivity of $61.7 \%$ and specificity of $58.8 \%$ (area under the curve [AUC]: 0.649 and $P=0.001$ ). HgA1C value of $>7$ predicted EFT thickness $\geq 4.15 \mathrm{~mm}$ with a sensitivity of $60.7 \%$ and specificity of $60.4 \%$ (AUC: 0.651 and $P<0.001$ ). No correlation found between RDW and HgA1C (AUC: 0.554 and $P: 0.169$ ). Conclusion: EFT thickness increased in diabetic patients, independent of age, gender, waist circumference, body mass index, and it was correlated with RDW and HgA1C.

Keywords: Epicardial fat tissue thickness, red blood cell distribution width, type 2 diabetes mellitus

\section{INTRODUCTION}

Epicardial fat tissue (EFT) is a small yet functional visceral fat depot which has different properties from other fat depots. Due to its paracrine and vasocrine activities, it plays a prominent role in inflammatory and atherosclerotic processes. ${ }^{[1,2]}$ Previous studies have shown that EAT thickness is higher in diabetic patients. ${ }^{[3]}$

Red blood cell distribution width (RDW) which is used for measuring the size heterogeneity of the erythrocytes could be obtained readily from full blood count. Greater heterogeneity of cell size yields larger RDW. It is identified as a reflection of chronic inflammation and evidence suggests that higher levels are closely related to the elevated high-sensitivity-C-reactive

Submission: 15-Nov-18 Revision: 17-Jan-19 Accepted: 05-Feb-19

\begin{tabular}{|l|l|}
\hline \multicolumn{3}{|c|}{ Access this article online } \\
\hline Quick Response Code: & Website: \\
\hline & \\
&
\end{tabular}

protein and erythrocyte sedimentation rate levels. ${ }^{[4]}$ Increased RDW level independently predict the poorer outcome in ischemic heart disease, congestive heart failure, peripheral artery disease, and in-stent restenosis..$^{[5]}$

Diabetes mellitus (DM) is a serious disease that is associated with important complications and its incidence increasing rapidly. It affects both macro- and microcirculation and has serious long-term complications. Hyperglycemia reduces

Address for correspondence: Dr. Cennet Yildiz, Department of Cardiology, Tekden Hospital, Istanbul, Turkey. E-mail: cennet_yildiz@live.com

This is an open access journal, and articles are distributed under the terms of the Creative Commons Attribution-NonCommercial-ShareAlike 4.0 License, which allows others to remix, tweak, and build upon the work non-commercially, as long as appropriate credit is given and the new creations are licensed under the identical terms.

For reprints contact: reprints@medknow.com

How to cite this article: Yildiz A, Yildiz C, Karakurt A. The relationship between epicardial fat tissue thickness and red blood cell distribution width in patients with Type 2 diabetes mellitus. Int J Cardiovasc Acad 2019;5:47-51. 
the lifespan of erythrocytes leading to volume changes. ${ }^{[6]}$ Among patients with DM, increased RDW levels indicate poor glycemic control..$^{[7,8]}$ In our study, we have attempted to investigate the possible differences in variables such as RDW and EFT thickness between diabetic and healthy patients and to assess the correlation (if any) between those parameters.

\section{Materials and Methods}

One hundred and fifty-nine type II diabetic patients and 153 healthy counterparts were enrolled in this single-center, prospective study. The study was approved by Kafkas University Medical Faculty ethical commitee (ethical committee number: 80576354-050-99, approval date: 14/03/2008). Clinical and demographic variables, medical history, and concomitant medications of the patients were measured at baseline. Data regarding diabetes duration and medications taken by the diabetic patients were also recorded. Diagnosis of type II DM was made according to the American Diabetes Association criteria. ${ }^{[9]}$ Patients with anemia (hemoglobin $<12 \mathrm{~g} / \mathrm{dl}$ ), chronic renal failure, obesity, congestive heart failure, active infection, chronic inflammatory diseases, malignancy, history of coronary artery bypass graft or percutaneous intervention, previous myocardial infarction, and stable or unstable angina were excluded from the study.

Fasting blood samples were drawn from the antecubital vein with the patient resting in the supine position. All specimens were analyzed on the same day in the biochemistry laboratory. Biochemical analysis was performed by Cobas c311 (Roche Diagnostics, Germany) and the following parameters were measured: fasting glucose, hemoglobin A1c, C-reactive protein, creatinine, total cholesterol, high-density lipoprotein cholesterol (HDL-C), triglyceride (TG), and low-density lipoprotein cholesterol (LDL-C). The blood parameters of all participants including hemoglobin, RDW, and platelet count, were studied by Cell-Dyn 3700 (Abbott Laboratories, Abbott Park, Illinois, USA).

All patients had 12-lead resting electrocardiogram in the supine position and had complete echocardiographic examination (Vivid 3 pro, GE Vingmed Ultrasound AS, Horten, Norway). The same cardiologist who was blinded to the clinic of the patients was performed the echocardiographic examination based on the recommendations of the American Society of Echocardiography. ${ }^{[10]}$ Simpson rule was used for calculating the left ventricular ejection fraction (LVEF). EFT was appeared as the hyperechoic space in the anterior face of the right ventricle, and its thickness was measured perpendicularly ahead of the right ventricular free wall, at the end-diastole from the parasternal long- and short-axis views. ${ }^{[1]}$

Continuous variables were presented as mean and standard deviation. Categorical variables were reported as percentages. Student's $t$-test was used to compare the parametric continuous variables. Nonparametric continuous variables and categorical variables were compared by Mann-Whitney U-test and Chi-square test, respectively. Pearson's correlation test was used to examine the correlation between the variables. For the cutoff values RDW and EFT, ROC curve analysis was used. All confidence intervals were $95 \%$. $P<0.05$ was regarded as statistically significant. All statistical analyses were performed using the SPSS program v. 15.0 (SPSS Inc., Chicago, IL, USA).

\section{RESULTS}

The study sample consisted of 312 patients. Among 159 diabetic patients, 65 were male, 94 were female, and among 153 control patients, 67 were male and 86 were female. Clinical characteristics of the patients such as age, sex, smoking, body mass index (BMI), systolic blood pressure, and LVEF were similar between the two groups. All the patients were on sinus rhythm during the study entry. Diastolic blood pressure of the diabetic patients was significantly higher than the healthy participants [Table 1].

Diabetic patients had increased EFT thickness $(4.3 \pm 1.1 \mathrm{~mm}$ vs. $3.7 \pm 1.0 \mathrm{~mm} P=0.001)$, higher RDW values $(13.5 \pm 0.7$ vs. $13.2 \pm 0.7 P=0.001)$, LDL-C, TG, and

\begin{tabular}{lccc}
\hline \multicolumn{4}{c}{ Table 1: Baseline characteristics of the patients } \\
\hline & $\begin{array}{c}\text { Diabetic group } \\
(\boldsymbol{n}=\mathbf{1 5 9})\end{array}$ & $\begin{array}{c}\text { Control group } \\
(\boldsymbol{n}=\mathbf{1 5 3})\end{array}$ & $\boldsymbol{P}$ \\
\hline Age (years) & $51.9 \pm 7.6$ & $51.4 \pm 6.5$ & 0.061 \\
Female, $n(\%)$ & $94(62.6)$ & $86(56.2)$ & 0.343 \\
Male, $n(\%)$ & $65(37.4)$ & $67(43.8)$ & 0.343 \\
LVEF (\%) & $64.3 \pm 8.2$ & $65.4 \pm 7.4$ & 0.86 \\
Smokers, $n(\%)$ & $43(28.6)$ & $42(27.7)$ & 0.831 \\
BMI (kg/m $)$ & $28.5 \pm 1.3$ & $28.4 \pm 1.2$ & 0.062 \\
SBP (mmHg) & $130.3 \pm 10.3$ & $126.3 \pm 11.4$ & 0.08 \\
DBP (mmHg) & $77.0 \pm 7.7$ & $73.5 \pm 8.1$ & 0.018 \\
\hline
\end{tabular}

BMI: Body mass index, DBP: Diastolic blood pressure, LVEF: Left ventricular ejection fraction, SBP: Systolic blood pressure

\begin{tabular}{|c|c|c|c|}
\hline & $\begin{array}{l}\text { Diabetic } \\
(n=159)\end{array}$ & $\begin{array}{c}\text { Nondiabetic } \\
(n=153)\end{array}$ & $P$ \\
\hline $\mathrm{TG}(\mathrm{mg} / \mathrm{dl})$ & $149.7 \pm 13.1$ & $139.9 \pm 13.2$ & $<0.001$ \\
\hline LDL-C (mg/dl) & $143.5 \pm 14.8$ & $128.2 \pm 16.0$ & $<0.001$ \\
\hline HDL-C (mg/dl) & $43.4 \pm 5.5$ & $44.6 \pm 6.1$ & 0.051 \\
\hline WBC count $\left(10^{9} / \mu 1\right)$ & $8.1 \pm 1.1$ & $7.8 \pm 1.0$ & 0.065 \\
\hline RDW (\%) & $13.5 \pm 0.7$ & $13.2 \pm 0.7$ & 0.001 \\
\hline Hemoglobin $(g / 1)$ & $13.2 \pm 0.7$ & $13.4 \pm 0.7$ & 0.081 \\
\hline Platelet count $\left(10^{9} / \mu 1\right)$ & $260.3 \pm 50.3$ & $258.5 \pm 53.4$ & 0.764 \\
\hline FPG (mg/dl) & $106.5 \pm 18.6$ & $86.3 \pm 10.9$ & $<0.001$ \\
\hline A1c (\%) & $7.3 \pm 0.8$ & $4.9 \pm 1.0$ & $<0.001$ \\
\hline C-reactive protein $(\mathrm{mg} / \mathrm{l})$ & $2.6 \pm 2.1$ & $2.2 \pm 1.8$ & 0.09 \\
\hline Creatinine (mg/dl) & $0.91 \pm 0.24$ & $0.87 \pm 0.21$ & 0.09 \\
\hline $\mathrm{EFT}(\mathrm{mm})$ & $4.3 \pm 1.1$ & $3.7 \pm 1.0$ & 0.001 \\
\hline
\end{tabular}

Measuring units and reference ranges: WBC count: $4-11 \times 10^{9} / \mu \mathrm{L}$, platelet count: $140-440 \times 10 \% / \mu \mathrm{L}, \mathrm{RDW}: 11 \%-14 \%$. EFT: Epicardial fat thickness, FPG: Fasting plasma glucose; HDL-C: High-density lipoprotein cholesterol, LDL-C: Low-density lipoprotein cholesterol, WBC: White blood cell, RDW: Red cell distribution width, TG: Triglyceride 
HgAlc levels compared to their healthy counterparts. Although HDL-C value was found to be higher in the control group, it did not carry statistical significance. The results of the serum biochemistry and hematological indices are shown in Table 2.

On correlation analysis, RDW and EFT $(0.384, P<0.001)$ were strongly positively correlated. RDW was also positively correlated with LDL-C, TG, and HgA1c levels and negatively correlated with HDL-C level. Parameters that are correlated with RDW are listed in Table 3. RDW value of 13.55 predicted EFT thickness $>5 \mathrm{~mm}$ with a sensitivity of $61.7 \%$ and specificity of $58.8 \%$ ( $P: 0.001$, Area under the curve [AUC]: 0.649, CI 95\%: 0.564-0.733) [Figure 1]. HgA1C value of $>7$ predicted EFT thickness $\geq 4.15 \mathrm{~mm}$ with a sensitivity of $60.7 \%$ and specificity of $60.4 \%$ (AUC: 0.651 vs. $P<0.001$ ) [Figure 2]. According to the power analysis, the strength to EFT in predicting the diabetic patients (alpha value $=0.05$ and $95 \%$ confidence) was $99.9 \%$.

\section{Discussion}

Our study showed that EFT thickness increased in diabetic patients, independent of age, gender, waist circumference, BMI, and it was correlated with RDW. As far as our best knowledge from the literature, our study is the first study showing a positive relation between EFT thickness and RDW

\section{Table 3: Parameters that are correlated with red cell distribution width}

\begin{tabular}{lcc}
\hline & $\boldsymbol{r}$ & $\boldsymbol{P}$ \\
\hline EFT thickness $(\mathrm{mm})$ & 0.402 & $<0.001$ \\
HDL-C $(\mathrm{mg} / \mathrm{dl})$ & -0.235 & 0.003 \\
LDL-C $(\mathrm{mg} / \mathrm{dl})$ & 0.398 & $<0.001$ \\
TG $(\mathrm{mg} / \mathrm{dl})$ & 0.134 & 0.05 \\
WBC count $\left(10^{9} / \mu \mathrm{l}\right)$ & 0.311 & $<0.001$ \\
\hline
\end{tabular}

EFT: Epicardial fat tissue, HDL-C: High-density lipoprotein cholesterol, LDL-C: Low-density lipoprotein cholesterol, TG: Triglyceride, WBC: White blood cell

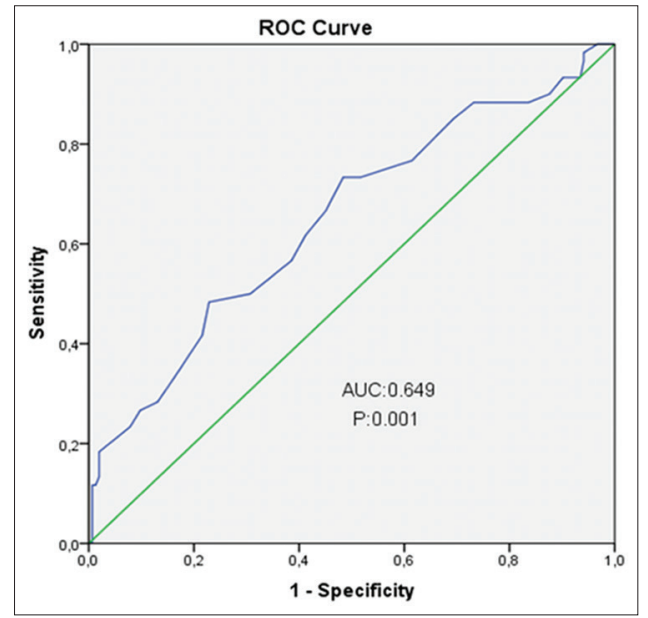

Figure 1: Receiver-operating characteristic curve analysis of red blood cell distribution width value to predict epicardial fat tissue $\geq 5 \mathrm{~mm}$ in diabetic patients. EFT has both paracrine and vasocrine activities and secretes a range of chemokines such as tumor necrosis factor- $\alpha$, interleukin- 6 , interleukin- $1 b$, monocyte chemoattractant protein-1, angiotensin II, and resistin. ${ }^{[2,12,13]}$ It has been suggested to influence atherosclerotic lesion progression, plaque vulnerability, and destabilization. ${ }^{[14]}$ Echocardiographic- and computed tomography (CT)-derived measurements of the epicardial adipose tissue (EAT) thickness have been found to be in correlation with the fasting blood glucose levels. ${ }^{[15]}$ Diabetic patients have increased EFT thickness as compared to nondiabetic participants, and it has a positive correlation with HbA1c levels. ${ }^{[16]}$ Arpaci et al. ${ }^{[17]}$ reported that prediabetic patients had higher EFT values which were directly correlated with the patients' BMI and waist circumference. Another study led by Altın et al..$^{[18]}$ investigated the relationship between fasting glucose levels and EFT and carotid intima-media thickness (CIMT) in prediabetic patients. In that study, prediabetic patients had higher EFT and CIMT, indicating that these two cardiovascular risk parameters could be used for risk stratification in that patient group. Studies have found positive relationship between EAT thickness and plasma level of insulin, retinol binding protein 4 , and mRNA expression of resistin which are associated with insulin resistance. ${ }^{[19-21]}$

EFT might be a modifiable risk factor or a target to modify cardiovascular risk. EFT and CIMT values of the asymptomatic obese patients were shown to be decreased after significant weight loss. ${ }^{[22]}$ Weight loss reverses the insulin resistance and decrease of EAT thickness in patients with metabolic syndrome. ${ }^{[19]}$ Serial measurement of EFT during follow-up of the patients may give additional information about their cardiovascular risk profile.

RDW is an indicator of erythrocyte anisocytosis, can be easily calculated from complete blood count. It has been found to have prognostic value in several diseases, such as coronary artery disease, left ventricular systolic failure, cerebrovascular disease, and chronic obstructive pulmonary

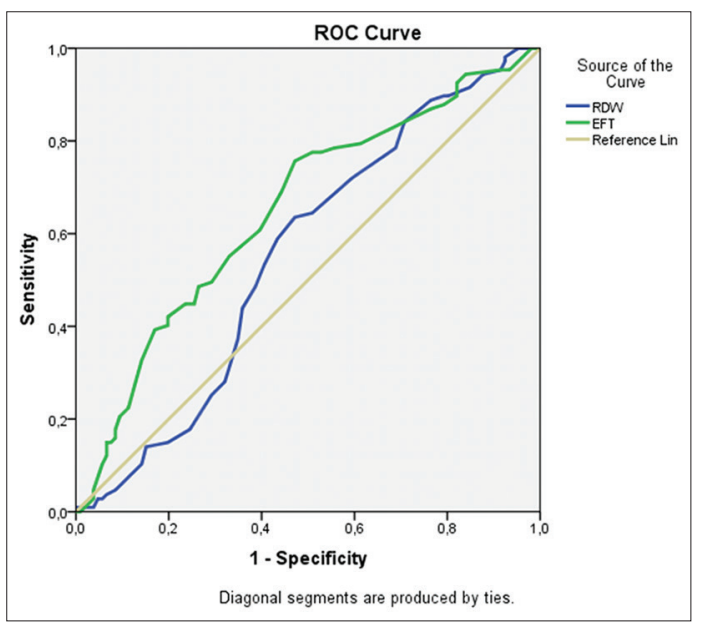

Figure 2: Receiver-operating characteristic curve analysis of $\mathrm{HgA1}$ c value to predict epicardial fat tissue $\geq 4.15 \mathrm{~mm}$ 
Yildiz, et al.: Epicardial fat tissue in diabetics

disease. ${ }^{[23-25]}$ Chronic inflammation underlying these diseases cause erythrocyte deformability and ineffective erythropoiesis which in turn leads to anisocytosis (high RDW). ${ }^{[4]}$

Diabetic patients have higher RDW values when compared with normal participants. ${ }^{[26]}$ Chronic hyperglycemia occurring in DM has several effects on erythrocytes, including glycosylation of hemoglobin, ${ }^{[27]}$ impaired deformability, increased aggregation, and decreased circulatory half-life. ${ }^{[6]}$ Nada. ${ }^{[26]}$ reported that RDW levels were significantly high in diabetic patients than in control subjects and it was positively correlated with $\mathrm{HbA} 1 \mathrm{c}$ levels.

EFT volume is higher in males, elderly, obese persons, as well as in diabetic and metabolic syndrome patients. ${ }^{[28-30]}$ Although our study and control group were similar with respect to their age, sex, and BMI values, diabetic patients had an increased EFT thickness, which showed a correlation with RDW. The cytokines secreted by EFT affect erythropoiesis, erythrocyte volume, erythrocyte lifespan, and thus promoting anisocytosis (high RDW) ${ }^{[31-33]}$ It is known that glycosylation of the hemoglobin reduces the lifespan of the erythrocytes. ${ }^{[7,8]}$ It can be speculated that, hormonal activity of EFT, glycosylation of hemoglobin, and increased oxidative stress in diabetic patients could cause RDW level elevation.

$\mathrm{DM}$ is a metabolic disease which imposes substantial socioeconomic burden as a result of its complications. We showed that type II diabetic patients had higher EFT thickness and RDW levels when we compared them with the normal individuals. Moreover, EFT thickness was positively correlated with RDW. It has been shown that both EFT and RDW have prognostic value for ischemic heart disease, in-stent restenosis, congestive heart failure, and peripheral arterial disease. Therefore, measurement of EFT thickness and RDW in patients with DM may provide additional prognostic information.

\section{Limitations}

The limitations of the study include the following: (1) It was a single-center study; (2) the study contained a relatively small number of patients; (3) EFT thickness was not measured by multislice $\mathrm{CT}$ and/or magnetic resonance imaging in our study patients; (4) we did not separate the diabetic patients according to their medical treatment. Hence, we could not compare the patients in two groups with insulin therapy or only oral antidiabetics; and (5) we did not evaluate the duration of disease, we could not make the correlation analysis between disease duration and EFT.

\section{Financial support and sponsorship}

Nil.

\section{Conflicts of interest}

There are no conflicts of interest.

\section{References}

1. Cheng VY, Dey D, Tamarappoo B, Nakazato R, Gransar H, Miranda-Peats R, et al. Pericardial fat burden on ECG-gated noncontrast $\mathrm{CT}$ in asymptomatic patients who subsequently experience adverse cardiovascular events. JACC Cardiovasc Imaging 2010;3:352-60.

2. Rabkin SW. Epicardial fat: Properties, function and relationship to obesity. Obes Rev 2007;8:253-61.

3. Song DK, Hong YS, Lee H, Oh JY, Sung YA, Kim Y, et al. Increased epicardial adipose tissue thickness in type 2 diabetes mellitus and obesity. Diabetes Metab J 2015;39:405-13.

4. Lippi G, Targher G, Montagnana M, Salvagno GL, Zoppini G, Guidi GC, et al. Relation between red blood cell distribution width and inflammatory biomarkers in a large cohort of unselected outpatients. Arch Pathol Lab Med 2009;133:628-32.

5. Yildiz A, Tekiner F, Karakurt A, Sirin G, Duman D. Preprocedural red blood cell distribution width predicts bare metal stent restenosis. Coron Artery Dis 2014;25:469-73.

6. Jabeen F, Rizvi HA, Aziz F, Wasti AZ. Hyperglycemia induced variations in hematological indixes in Type 2 diabetics. Indian J Appl Res 2013;1:322-34.

7. Veeranna V, Zalawadiya SK, Panaich SS, Ramesh K, Afonso L. The association of red cell distribution width with glycated hemoglobin among healthy adults without diabetes mellitus. Cardiology 2012;122:129-32.

8. Lippi G, Targher G, Salvagno GL, Guidi GC. Increased red blood cell distribution width (RDW) is associated with higher glycosylated hemoglobin (HbA1c) in the elderly. Clin Lab 2014;60:2095-8.

9. American Diabetes Association. Standards of medical care in diabetes-2016. Diabetes Care 2016;39 Suppl 1:S1-106.

10. Schiller NB, Shah PM, Crawford M, DeMaria A, Devereux R, Feigenbaum $\mathrm{H}$, et al. Recommendations for quantitation of the left ventricle by two-dimensional echocardiography. American Society of Echocardiography Committee on Standards, Subcommittee on Quantitation of Two-Dimensional Echocardiograms. J Am Soc Echocardiogr 1989;2:358-67.

11. Eroğlu S. How do we measure epicardial adipose tissue thickness by transthoracic echocardiography? Anatol J Cardiol 2015;15:416-9.

12. Wheeler GL, Shi R, Beck SR, Langefeld CD, Lenchik L, Wagenknecht LE, et al. Pericardial and visceral adipose tissues measured volumetrically with computed tomography are highly associated in type 2 diabetic families. Invest Radiol 2005;40:97-101.

13. Yudkin JS, Eringa E, Stehouwer CD. "Vasocrine" signalling from perivascular fat: A mechanism linking insulin resistance to vascular disease. Lancet 2005;365:1817-20.

14. Verhagen SN, Visseren FL. Perivascular adipose tissue as a cause of atherosclerosis. Atherosclerosis 2011;214:3-10.

15. Wang TD, Lee WJ, Shih FY, Huang CH, Chang YC, Chen WJ, et al. Relations of epicardial adipose tissue measured by multidetector computed tomography to components of the metabolic syndrome are region-specific and independent of anthropometric indexes and intraabdominal visceral fat. J Clin Endocrinol Metab 2009;94:662-9.

16. Iacobellis G, Diaz S, Mendez A, Goldberg R. Increased epicardial fat and plasma leptin in type 1 diabetes independently of obesity. Nutr Metab Cardiovasc Dis 2014;24:725-9.

17. Arpaci D, Ugurlu BP, Aslan AN, Ersoy R, Akcay M, Cakir B, et al. Epicardial fat thickness in patients with prediabetes and correlation with other cardiovascular risk markers. Intern Med 2015;54:1009-14.

18. Altin C, Sade LE, Gezmis E, Ozen N, Duzceker O, Bozbas H, et al. Assessment of subclinical atherosclerosis by carotid intima-media thickness and epicardial adipose tissue thickness in prediabetes. Angiology 2016;67:961-9.

19. Liang KW, Tsai IC, Lee WJ, Lin SY, Lee WL, Lee IT, et al. Correlation between reduction of superior interventricular groove epicardial fat thickness and improvement of insulin resistance after weight loss in obese men. Diabetol Metab Syndr 2014;6:115.

20. Iacobellis G, Ribaudo MC, Assael F, Vecci E, Tiberti C, Zappaterreno A, et al. Echocardiographic epicardial adipose tissue is related to anthropometric and clinical parameters of metabolic syndrome: A new indicator of cardiovascular risk. J Clin Endocrinol Metab 2003;88:5163-8

21. Salgado-Somoza A, Teijeira-Fernández E, Rubio J, Couso E, González-Juanatey JR, Eiras S, et al. Coronary artery disease is associated with higher epicardial retinol-binding protein 4 (RBP4) and lower glucose transporter (GLUT) 4 levels in epicardial and 
subcutaneous adipose tissue. Clin Endocrinol (Oxf) 2012;76:51-8.

22. Altin C, Erol V, Aydin E, Yilmaz M, Tekindal MA, Sade LE, et al. Impact of weight loss on epicardial fat and carotid intima media thickness after laparoscopic sleeve gastrectomy: A prospective study. Nutr Metab Cardiovasc Dis 2018;28:501-9.

23. Tonelli M, Sacks F, Arnold M, Moye L, Davis B, Pfeffer M, et al. Relation between red blood cell distribution width and cardiovascular event rate in people with coronary disease. Circulation 2008;117:163-8.

24. Ani C, Ovbiagele B. Elevated red blood cell distribution width predicts mortality in persons with known stroke. J Neurol Sci 2009;277:103-8.

25. Seyhan EC, Özgül MA, Tutar N, Ömür I, Uysal A, Altin S, et al. Red blood cell distribution and survival in patients with chronic obstructive pulmonary disease. COPD 2013;10:416-24.

26. Nada AM. Red cell distribution width in type 2 diabetic patients. Diabetes Metab Syndr Obes 2015;8:525-33.

27. Shin $\mathrm{S}, \mathrm{Ku} \mathrm{Y}$, Babu N, Singh M. Erythrocyte deformability and its variation in diabetes mellitus. Indian J Exp Biol 2007;45:121-8.

28. Iacobellis G, Willens HJ. Echocardiographic epicardial fat: A review of research and clinical applications. J Am Soc Echocardiogr 2009;22:1311-9.

29. Versteylen MO, Takx RA, Joosen IA, Nelemans PJ, Das M, Crijns HJ, et al. Epicardial adipose tissue volume as a predictor for coronary artery disease in diabetic, impaired fasting glucose, and non-diabetic patients presenting with chest pain. Eur Heart J Cardiovasc Imaging 2012;13:517-23.

30. Fox CS, Gona P, Hoffmann U, Porter SA, Salton CJ, Massaro JM, et al. Pericardial fat, intrathoracic fat, and measures of left ventricular structure and function: The Framingham heart study. Circulation 2009;119:1586-91.

31. Förhécz Z, Gombos T, Borgulya G, Pozsonyi Z, Prohászka Z, Jánoskuti L, et al. Red cell distribution width in heart failure: Prediction of clinical events and relationship with markers of ineffective erythropoiesis, inflammation, renal function, and nutritional state. Am Heart J 2009;158:659-66.

32. Vayá A, Sarnago A, Fuster O, Alis R, Romagnoli M. Influence of inflammatory and lipidic parameters on red blood cell distribution width in a healthy population. Clin Hemorheol Microcirc 2015;59:379-85.

33. Emans ME, van der Putten K, van Rooijen KL, Kraaijenhagen RJ, Swinkels D, van Solinge WW, et al. Determinants of red cell distribution width (RDW) in cardiorenal patients: RDW is not related to erythropoietin resistance. J Card Fail 2011;17:626-33. 